\title{
The Status and Challenges of Women's Sport Leadership In Ethiopia National Sport Organizations
}

\author{
Mlashu Tsegay ${ }^{1 *}$, KesatieLegesse $^{2}$, AbebeEjigu ${ }^{3}$, Mathivanan $^{4}$ \\ 1 Research Scholar, Department of Sport Science, Woldia University, Woldia, Ethiopia. \\ 2 Associate Professor, Department of Sport Science, Mekelle University, Mekelle, Ethiopia \\ 3 Associate Professor, Department of Management, Mekelle University, Mekelle, Ethiopia. \\ 4 Assistant Professor, Department of Sport Science, Mekelle University, Mekelle, Ethiopia
}

\begin{abstract}
Leadership is the process of influencing an organized group toward accomplishing common set of goals, and it can also be defined as the ability of an individual to establish direction for a working group of individuals who gain commitment from this group of members to this direction and who then motivate these members to achieve the direction's outcomes. The purpose of the Current study was to investigate the status and challenges of women leaders in national sport organizations. Data were collected through questionnaires, in-depth, face to face semi structured interviews, observations and document analysis from 216 men and women leaders and experts in organizations. Qualitative and quantitative data was used to determine the challenges of Women's leadership s in Ethiopia national sport organization.data analysis focused on the groups that emerged from the collected data. Therefore, thematic analysis was used to accomplish main goals. And descriptive statistics was used in data analysis. This entails the use of frequency distribution tables and percentages to summarize data on the closed ended items in the questionnaire. Analysis of data employed Statistical Package for Social Scientists (SPSS) version 20 softwarewere used to describe the results. The findings showed that the status of women's in the organization is very low. Challenges that hinder women's participation in national sport organization includepersonal limitations; lack of professional networks, lack of budget,family responsibilities, socio-cultural factors consisting of traditional practices and society's perceptions on women's..
\end{abstract}

Keywords: Women, Leadership, status, Sports organization, challenge

Article Received: 20 September 2020, Revised: 30 November 2020, Accepted: 18 December 2020

\section{Introduction}

Several political orators, educational thinkers, business executives, social workers, and scholars have used the word leadership. The word lead, leader, and leadership come from the Anglo- Saxon word "lead", meaning "path" or "road", and the verb leader means "to travel" (Kets de Vries, 2006: 2). Thus, leader is one who shows fellow travelers the way by walking ahead. The history of leadership theories started from the "The Great Man" theory of the mid 1800s which assumed as trait theory (leaders are born not made), behavioral theory (there is one best way to lead), situational/contingency theory (leaders act differently depending on the situations), to the recently introduced theories- leader is rational, transformative, and empowering (Dr. Sushanta K. 2012). Leadership and its role are the most concerning issues for business and organizations nowadays. The " leaders are individuals who establish direction for a working group of individuals and who gain commitment from this group of members to established direction and who then motivate members to achieve the direction's out comes "(Conger,1992: 18). The term leadership can be viewed through multiple angles and concepts. Traditionally leadership is a set of feature owned by the leader or it is a social phenomenon that comes from relationship with groups. These concepts can give different opinions about the definition of leadership. It is a continuous debate that whether the leadership comes from the personal qualities of leader or a leader makes followership through what he/she does or believes (Grint 2004). Grint also highlight position problems with the leadership, through which explores, is the leader a person in charge? With a true authority to decide or implement or it is only a person in front who takes his/her directions for some one. 
Recent reviews take leadership as "a process whereby an individual influences a group of individuals to achieve a common goal (Nort house 2004)". Another view about leadership is that "Leadership is like the abominable snowman, whose foot prints are everywhere but who is nowhere to be seen" (Bennis and Nanus 1995).

\section{Back grounds of the study}

Leadership is the process of influencing an organized group toward accomplishing common set of goals, and it can also be defined as the ability of an individual to establish direction for a working group of individuals who gain commitment from this group of members to this direction and who then motivate these members to achieve the direction's outcomes. (Aman et al ,2019)Women leadership is just one branch of this concept and can also be defined in different ways(Elsi lahti, 2013)and Sports leadership is one of the component parts of general leadership. In addition,the representation of women has been increasing in many areas of the work force as well as higher education. However, the number of women in the highest leadership roles in almost all occupational areas is not increasing in proportion to their overall numbers in education or the work force and this under representation of women is also evident in the area of sport. Sport has traditionally been a male dominant, thus leadership roles within sport are primarily masculine in nature (Massengale, 2009;Burton, 2014).

As various researchers indicated, male dominated leadership implies low representation of women in positions of power. The social, historical, cultural and structural factors appear to contribute to the marginalization of women in leadership, with these factors being categorized under the organizational, relational and individual barriers labels (M'Mbaha, 2012). Throughout the world, women are a small minority within the governing bodies of organized sport (Taylor et al.,2009).

The depth and breadth of scholarship examining the underrepresentation of women in leadership positions in sport organizations illustrates the complexity of the issue. women continue to face(David, 2009) challenges and obstacles are seeking leadership positions in sport organizations (Burton, 2015). Researchers have noted a significant improvement in numbers for women in leadership positions, but in sport there is still a long way to go. Women are still underrepresented in leadership (Mugari \& Masocha, 2015).

The national sport policy of 1998 also gives due attention to ensure the women direct participation and equal benefit in all sport activities. But the majority of leadership position is dominated by men in Ethiopia including sport organization; women who constitute fifty percent of Ethiopian population are underrepresented in decision making position at all level of governance. The status and challenges of women leadership is not studied in the country even policy makers are not properly designed women leadership in sport organization to enhance the country transformation through multiple directions.

Ethiopia Growth and transformation plan II(GTP) give priority to women participation for transformation including sport leadership is given higher priority in the country. But there are a lot of obstacles to hinder them from getting leadership position in sport organization. Furthermore, there is huge plan of sport as income generation and job opportunity for youngsters in the country for the coming GTP II transformation plan. Therefore participation of women in sport leadership could be successful achievements of the plan.

\section{Significance of the study}

The result of this study is vital for women working in sports federation and association to identify their status in organizations.

This information can be useful to officials in sport organizations. ,

It helps the Government to design policies and feasible working plans so that the status of women in leadership will improve.

Women themselves will be benefited in having awareness about leadership. And It will help them to see their status from modern management aspects and its implementation, 
To identify the leader ship challenges within and outside their organization and also the ways in solving these problems. It allows women to develop their own business development plan according to the country policy,

The study also helps scholars and experts as a spring board to prepare discussions, seminars and workshops. It will also initiate other researchers for further research related with such problems. .

This study is important for empowering women in leadership.

Reviews of Related Literature Women in Leadership: Understanding the gender gap

As organizations continue to set diversity strategies, it is crucial to understand why the gap still exists. Identifying and understanding the gender gap will go a long way in assisting business and government to formulate optimal policies to address the gender gap, and to capitalize on the opportunities of a more diverse workplace and talent pool. Gender diversity policies can also pave the way for broader diversity policies. (gender gap," 2013)

The Global Center for Social Change through Women's Leadership and Sport has demonstrated that it is committed to the development of women on all continents and we are grateful for the role model and guidance they provide in attempting to make the world a better place through sport and leadership development(Burton, 2015)

The major reason for underrepresentation of women in leadership and decision making position is relatively they have less freedom because of their family responsibility. Mainly, gender-based discrimination at many levels prevents women from getting senior positions traditionally held by men. Most women not have the level of education necessary for entry to level of leadership positions in the public sector. Opportunities should be given for women to increase their education level to fit whatever decision making positions they are supposed to join. The concerned women are also responsible to update themselves and equally compete with their men counter parts. Because of some of our traditional thoughts regarding women performance sometimes gender- based discriminations happens. Such thoughts should be avoided and all stakeholders should cooperate women in all aspects. Major challenges influencing women were cultural issues become more obvious especially if the female works in a different cultural set up. It is followed by some male colleague do not give them support and lack of parental involvement to follow up and cooperate them in all as pacts' becomes common in female headed institutions. Parents should have a time and develop concern to follow up and cooperate them in all aspects(Eba, 2012)Research has focused extensively on the barriers that women face in attaining leadership positions. Perceptions of sport as a male domain perpetuate the ongoing discrimination. With men hold- ing dominant roles in sport, girls often do not view athletics as a viable career path and boys do not perceive(Massengale, Lough, Massengale, \& Lough, 2017)

Findings also indicated that girls and women face gender-based barriers due to their personal (dependent) socio-economic situation. Lack of transport (money) or the time and opportunity to work for transport money, as well as lack of proper, adequate facilities and equipment hinder female involvement in sport. Traditional Zambian dress codes for girls and (married) women seem to restrict many girls and women from participating in sport, due to lack of personal resources(Jacobsen \& Studies, 2014)

\section{Research Methodology}

\section{Description of the study area}

This study focused on status and challenges of Women in Sport Leadership Positions in Ethiopia national sport organization.

Therefore, the study was carried out in Ethiopian national sport organizations, who are working at federation, association and committee level. Ethiopian national sport organizations contained 27 national sport organizations those include 21 federations, 4 Associations and 2 committees. These organizations are found in the capital city of Ethiopia, Addis Ababa. The total members of Ethiopian national sport organizations contained 216 people with 162 executive federation members, 27 general secretary and 27 experts.sources sport association, recognition and support directorate(ASRSD), (2010). 


\section{Research Design}

This project used a descriptive survey design. According to Churchill (1991), survey research design is appropriate where the study seek to describe the characteristics of a certain group, estimate proportion of people who have certain characteristics and make certain predictions. It describes the situation without manipulation. According to Mugenda (2003) survey research designs seeks to obtain information that discloses existing phenomenon by asking individuals about their perception, attitude and behavior.

This design is preferred because very large samples are feasible which make the results statistically significant when analyzing multiple variables. Additionally, high reliability is easy to obtain by subjecting all subjects with a standardized stimulus, which ensures that observer's subjectivity is greatly eliminated (Mugenda, 2008).

\section{Data Collection Instruments}

The study employed both qualitative data collected from both primary and secondary sources. A primary source was collected by structured, semi-structured questionnaire; key informant interview and documents analysis was used to collect data on status and challenges of Women in Sport Leadership Positions in Ethiopia national sport organizations.Interview was held to collect qualitative data from president, general secretary and experts of each organization.The sample of this population included both men's and women's Ethiopian national sport organizations leaders andexperts that have experience on sport leadership.

Population and Sampling technique

\begin{tabular}{|l|l|l|l|l|l|l|}
\hline Leaders & Men & Women & $\begin{array}{l}\text { The whole } \\
\text { population }\end{array}$ & $\begin{array}{l}\text { Number of } \\
\text { subjects to be } \\
\text { taken } \\
\text { size }\end{array}$ & $\begin{array}{l}\text { Samples } \\
\text { Sampling }\end{array}$ \\
\hline $\begin{array}{l}\text { Executive federation } \\
\text { Members }\end{array}$ & 154 & 8 & $6 \times 27$ & 6 & 162 & Comprehensive \\
\hline $\begin{array}{l}\text { Directors } \\
\text { (general secretary) }\end{array}$ & 24 & 4 & $1 \times 27$ & 1 & 27 & Comprehensive \\
\hline Experts & 21 & 5 & $1 \times 27$ & 1 & 27 & Comprehensive. \\
\hline Total & 199 & 17 & 216 & & & \\
\hline
\end{tabular}

Sources sport association, recognition and support directorate

\section{Reliability of the instruments}

The researcher distributes the instruments to president, vice presidents and department heads in Mekelle Universities to test reliability of the instruments. then correlated using pearson`s correlation formula and a reliability coefficient was established at 0.8 which is an indicator of a strong positive correlation with the objectives.

\section{Data collection procedure}

Data was collected using questionnaire and interview guide. A research authorization permission was obtained from Mekelle University departments of sport science, in order to be allowed to collect data from the organization. The researcher then proceeded to the field to collect data as per the schedule. Information collected was treated with confidentiality. The organizations were pre-visited by the researcher to establish rapport with them before the actual data collection date. Data Analysis

Data was systematically coded, tabulated and organized for analysis. The techniques were selected based on the nature of data collected and the basic research questions. Documents analysis and in-depth interview were transcribed and presented in a narrative form. The qualitative data was used to determine the status and challenges of Women's Leaderships in Ethiopia national sport organization.Because thenature of this study was narrative, data analysis focused on the groups that emerged from the collected data. 
Therefore, thematic analysis was used to accomplish two main goals. The coding of thematic narrative starts with analyzing each interview separately. First, the researchers familiarized themselves with each of the information in the transcripts by reading it many times. Second, the transcripts were divided into fragments and then categorized for each interview. Third, these categories were identified with codes, and then "the overlapped and redundant codes into general broad themes" were examined.

After the coding was complete for each interview, the codes were compared and emergent themes were sought among the participants' interviews. For this step, word document software was used to assist in the comparisons. After this was done, both transcriptions and the coding tables were printed, and then reviewed and compared to ef all the information for the sake of perception and accuracy.

Forty nine of the fifty fourwere interviewed one times; the other five participants did not do a follow-up interview. Each interview was conducted either faceto-face or by phone. Thirty nine participants chose their workplace, one participant chose her home, and the last remaining eight participants were interviewed by phone. They were also given the freedom to speak either in Amharic or English in conducting the interviews. Only one participant chose to speak in English. The other forty eight used Amharic language as a medium of communication.

During interview approximately ten to twelve minutes was used for follow-up questions, member checking, clarifications, and expansion. interview protocol was used to guide the interviewing process. The protocol for the interview had open-ended and close-ended questions related to the research questions of this study. Some of the interview questions on the interview protocol were adopted from Suzan Hassan(2014) doctoral study. During the interviews, notes were taken and one phone-recorder was used to record the interviews.

All the documented materials were saved on computer using secure and protective documents' passwords. Finally, the collected data was ready for analysis.

The purpose of this study wasto investigate the status and Challenges of Womens Sport Leadership in Ethiopia national sport organizations. In order to serve this purpose, the researcher prepared questionnaires and interviews for respondents to write their comments on the issues under consideration.

RESULTS AND DISCUSSION

\section{Questionnaires Results}

Table 4.1: Present status of women s' leadership in national sport organization of Ethiopia. $(\mathrm{N}=216)$

\begin{tabular}{|l|l|l|l|l|l|}
\hline \multirow{2}{*}{ Strength } & \multicolumn{5}{|c|}{ Number of respondents (216) } \\
\cline { 2 - 6 } & Very low & \multicolumn{1}{|c|}{ Low } & \multicolumn{1}{c|}{ Moderate } & \multicolumn{1}{c|}{ High } & Very high \\
\hline Frequency & 92 & 96 & 12 & 9 & 7 \\
\hline Percentage & 42.59 & 44.44 & 5.5 & 4.16 & 3.24 \\
\hline
\end{tabular}

As indicated in the above table 4.1, 87.03\% of the respondents stated their present status of women's leadership in national sport organizationis very low and low. Whereas, $7.4 \%$ of the respondents stated that the present status of women's leadership is very high and high. From the result the researcher reported that the present status of women in national sport organizationof Ethiopian national sport organization is very low. From this analysis the result of the respondents can be analyzed the status of women's leadership in Ethiopian national sport organization is very low.
Positions of the participants in the organization/ institution

Most of the participants' positions in the organizations were presidents, vice presidents property care (“akabiniway") general secretaries and experts.

\section{Challenges or barriers that slow the organizations}

Lack of Professional Networks

The challenges women and men's face when looking for leadership positions and opportunities are lack of access networks that let them to be excluded from the large professional networks and shortage of time forleadership trainings. 


\section{Lack of Effective Mentors}

The other challenge for the organization is the lack of effective mentors to all women and men who gain leadership and decision-making positions. Women leaders who achieved leadership lack of mentoring opportunities contribute to the underrepresentation of women in leadership positions. Additionally, they noted a positive relationship between mentors and mentees. They found the presence of effective mentors in individuals' careers can enhance their abilities, provide greater job satisfaction and promotion, increase self-confidence, and provide inside information and networks

Their results indicated that women received fewer career-development activities and less mentoring than men. Hence, organizations might accidentally deprive women through this lack of access to mentoring and career-development activities. Effective mentoring is a key to women advancement to leadership. The lack of mentoring can hinder progress and can divert their time and energy away from leadership positions mentoring provide valuable information; however, most of the time this information can be a source of help in national sport organization.

\section{Institutional Policies and Culture}

Institutional policies and culture makes the other challenge for the respondents to be promoted and obtain leadership positions, they need to adapt to the male-dominant culture. To demonstrate their ambitions and commitment to work and the organization, women are expected to make the "right choices" in dedicating their time to their work rather than being concerned with their own families and children. Other respondents indicated that a gender gap exists in national sportorganizations.

The Respondents also responded some common issues for these women, such as: lack of confidence in their abilities, silence as a result of not being able to get the post, ambivalence around valuing teaching and research more than leadership roles, challenges in balancing work requirements with personal life, and resistance as a result of the increase in on-demand administrative duties

Lack of budget, almost all of the respondents resigns this challenges many times. As they said budget is a back bone for the organization to facilitate the objectives of organization. but the government cannot prepare enough budget for the organization and the distribution of budget from organization to organization not equal for example the yearly budget for football federation is more than 1 million birr but yearly budget other federation is not more than one hundred thousand so the respondents states that there must be equal distribution of budget in all national sport organizations'. All participants considered the unequal distribution of resources between the organizations .and Lack of sufficient equipment's in each originations are the challenges for the respondents.

Interview results

\section{Obstacles related to Gender}

\section{Family Responsibilities}

The main challenges that affect women's participation in national sport organization, and in sport leadership positions particularly, is taking care of the family. This is especially challenging when women have young children. Many studies have addressed the issue of balancing personal life, children, and job requirements, especially for women leaders. In addition, many women have expressed their concern about the lack of organizational support, information, and policies for their parental role. They also have emphasized their fear to request arrangements that suit their needs and family obligations for fear of losing promotion opportunities to leadership positions. In contrast, male leaders tend to criticize women who try to balance family and work life. They believe that women with children are responsible for their own failure to reach leadership positions because, according to these men.

Second interview was asking for women leaders about the barriers of women leaders faced when interacting with men. The participants discussed those barriers as the result of being women and they had to undertake due to their gender when interacting with men regardless of their leadership positions. Most of the respondents list three barriers women leaders faced when interacting with men.

Power over resources is $\mathbf{1}^{\text {st }}$ barrier identified by all participants as a barrier when dealing with men since they were deputies of male leaders who had the power and authority in distributing the budget and resources. They explained the different distribution of budget 
between men and women. While men enjoyed the leverage of freedom in satisfying all their organizationfinancial needs, they gave for women less than they need.

Shortage of staff is the $\mathbf{2}^{\text {nd }}$ barriers to work with men the participants identified shortage of staffas a barrier when interacting with men. This shortage could be related to the factorssuch as limited administrative support, and work overload.

-The $3^{\text {rd }}$ was segregation between the two genders. The respondents considered segregation as a barrier when interacting with men in the workplace.

. As a result of this segregation, women had to wait for men's approval and decisions rather than her being able to decide for their organizations. They indicate that men's segregation resulted in a lack of their direct interaction with women. Therefore, men leaders did not have a full picture of their women counterpart's achievements. In contrast, they have full access to supervise men's work, which gave them the advantage over women. They stated:

Because of segregation, since men are not interacting directly with women, they don't have the full picture of what's going on. For example, when women requested a certain budget for an event or activity, the men leaders don't comprehend or visualize the need for that money. They think it is too much and keeps asking questions and even gives less because they are not involved in the process and can't access and see the event themselves. But men leaders won't face that questioning or have an issue because the leader can supervise and attend for themselves the event or activity.

Same the respondents also elaborated about the segregation between men and women. They described that this segregation caused separation between decision-making done by men and application done by women: main struggle is related to the separation between the leading and decision-making operations, where they take place on the men's organization.

. This segregation between men and women created a culture of lack of interaction between the two genders and lack of knowing and understanding one another. They believe that half of the success as a leader relates to the immediate contact and interaction between the leader and his/her staff. And because men don't interact with women in the organization, they can't see women's work and accomplishment; they don't have any experience in dealing with women as women in a professional manner and only depend on the way they deal and treat their women relatives, which is totally out-of-context. They only rely on paperwork, which is unfair in many cases because written work doesn't represent the actual performance, and also because in some occasions some of the written work may be lost or even hidden purposefully to harm that woman and undermine her hard efforts and performance.

To conclude the challenges section, the participants of this study varied in identifying the barriers they encountered when interacting with men in the workplace. However, regardless of the level of agreement between them, they all shared some type of barriers that hindered their performances as leaders because of their gender. Those constraints were due to these women leaders' social roles and gender stereotypes that forced them to deal with those barriers.

Mechanisms to be a leader in national sport organization

Most of the participants were being a leader through experience some of them were teachers, coaches, athletes, regional experts, instructors, university lecturers, almost all the respondents get leaders step by step no participant was being leader directly.

Types of leadership training before or when they became a leader

Most of the participant follows up many leadership training sponsored by the organization as well as by themselves. Those trainings include skill training, leadership training, instructor courses, coaching courses

Encouraging Future women Candidates to Leadership

Despite all the challenges related to women were expected to uphold in their workplace, Therefore, encouraging future women candidates to leadership. The participants' replies included their support and the qualities or the barriers that those newcomers need to be aware of. Leadership is very hard. It's really hectic because it takes a lot of your time. Socially, you get the prestigious position in the society but in reality it 
demands a lot of work, especially for a woman. It's a nice experience but it depends on your own style. Leadership is as a "hard" and "hectic" task "especially for a woman" even though it provided social prestige.

Making opportunities for the organizations

Most of the leaders make opportunities for the organization by introducing their organization objectives, their culture, and their country during international competitions.

\section{Targeting future perspective of women as a leader in national sport organization}

In order to produce outstanding leaders and managers,sport federations,sport associations and all stake holders should work together to increase women participation in leadership and training should given for women leader in national sport organization as well as in all parts of the country and leaders should know the objective of the organization.

\section{Discussions of findlings}

Present status of women's leadership in national sport organizationis very low and .Most of the respondents stated the present status of women's leadership in national sport organizationis very low and low. From the result the researcher reported that the present status of women in national sport organizationof Ethiopian national sport organization is very low. This finding was supported bylapchick(2007) states women are underrepresented in leadership areas in professional sport.

The challenges women and men's face when looking for leadership positions and opportunities lack of access networks they are excluded from the large professional networks.

The Respondents also responded some common issues for these women, such as lack of confidence in their abilities, silence as a result of not being able to get the post, ambivalence around valuing teaching and research more than leadership roles, challenges in balancing work requirements with personal life, and resistance as a result of the increase in on-demand administrative duties the above result was supported by Kiev, (2011).Women make up the majority of civil servantsat lower-level positions, requiring lower qualifications and not carrying significant responsibility. and supported by Muoli,(2015)and Williams (1987).their findings showed that lack of self-esteem among women and girls was one of the factors identified to have been preventing more women and girls from participating in sports organization and management.

Lack of budget, almost all of the respondents resigns this challenges many times. As they said budget is a back bone for the organization to facilitate the objectives of organization. but the government cannot prepare enough budget for the organization and the distribution of budget from organization to organization not equal for example the yearly budget for football federation is more than 1 million birr but yearly budget other federation is not more than one hundred thousand so the respondents states that there must be equal distribution of budget in all national sport organizations'. All participants considered the unequal distribution of resources between the organizations and lack of sufficient equipment's in each originations are the challenges for the respondents.The above result was supported by Doreen (2014). The results revealed that budget enables mobilization of resources and maximizes proper utilization of resources in the adequate and correct ways and that is facing the problem of being not having computerized budgeting software. According to the findings it is recommended that the organization should be carefully in setting the goals for the financial year by making sure that those goals must be achievable in order to avoid wastage of resources.

Family responsibilities is the main challenges that affects women's participation in national sport organization, and in sport leadership positions particularly, is taking care of the family. This is especially challenging when women have young children. Many studies have addressed the issue of balancing personal life, children, and job requirements, especially for women leaders. In addition, many women have expressed their concern about the lack of organizational support, information, and policies for 
their parental role. They also have emphasized their fear to request arrangements that suit their needs and family obligations for fear of losing promotion opportunities to leadership positions. In contrast, male leaders tend to criticize women who try to balance family and work life. They believe that women with children are responsible for their own failure to reach leadership positions,above result was supported by Conclusions

Based on the major findings the following conclusions were made:

As observed and analyzed previously The general objective of the study is to identify the status and challenges of women leadership in national sport organization.The result indicates that Women are under-represented in positions of leadership in the organization. The general challenges for the respondents in the organizations are, shortage of time for training. lack of sufficient equipment's in each Reference

1. Arimi, D. K. M. (2013). Factors Influencing Participation Of Women In Leadership In Secondary School Management In Lower Yatta District, Kitui County, Kenya.

2. Aman et al women in sport leadership positions in malaysia;issues and challenges. published Artice

3. Burton, L. J. (2014). Underrepresentation of women in sport leadership: A review of research. Sport Management Review, 1-11. https://doi.org/10.1016/j.smr.2014.02.004

4. Burton, L. J. (2015). Underrepresentation of women in sport leadership: A review of research. Sport Management Review, 18(2), 155

165.https://doi.org/10.1016/j.smr.2014.02.004

5. Choge, J. R. (2015). Gender Factor in Decision Making: Challenges Facing Women Leadership Development in Primary Schools ' Managemnt in Kenya, 6(12), 30-38.

6. Constitution, E. (1994). C ONSTITUTION OF $T$ HE $F$ EDERAL D EMOCRATIC $R$ EPUBLIC OF E THIOPIA, (December 1994).

7. Conger, S., (1992). Far-ultraviolet observations of the Crab Nebula using the Hopkins Ultraviolet Telescope Astrophysical
GaelleFerrant\&AnneliseThim,(2019).Gender gaps in unpaid care work begin at an early age for girls and boys, increasing for women at marriage and childbirth. For men, however, marriage may actually decrease their time spent on unpaid care work: married women spend less time on routine housework than single women do

organizations,lack of Professional Networks, lack of effective mentors, Institutional Policies and Culture, Family Responsibilities and Lack of budget in order to produce outstanding leaders and managers, sport federations,sport associations and all stake holders should work together to increase women participation in leadership and training should be given for women leader in national sport organization as well as in all parts of the country and leaders should know the objective of their organizations.

Journal, Part 1 (ISSN 0004-637X), vol. 399, no. 2, p. 611-620.

8. David, I. B. (2009). LEADERSHIP IN ORGANIZATIONS. Maryland: University Press of America, ${ }^{\circledR}$ Inc.

9. Denscombe, M. (2003). The Good Research Guide (second). England: McGraw-Hill Education.

10. De Vries MFRK. The spirit of despotism: Understanding the tyrant within. Human Relations. 2006;59(2):195-220. doi: $10.1177 / 0018726706062732$

11. Doreen, (2014). Effectiveness of budgeting process in achieving organizational goals: a case of Temesa

12. Dr. Sushanta K. (2012) Practice and Problems of Principals' Leadership Style and Teachers' Job Performance in Secondary Schools of Ethiopia, Bahir Dar University, Ethiopia.

13. Eba, M. Y. (2012). Practices and Challenges of Women in Leadership and Development Activities of Some Selected Woredas of Bench Maji Zone , Ethiopia, 3(10), 599-606.

14. Ehsani, M., \& Boshehri, N. S. (2016). European Journal of Physical Education and Sport Science effective factors on women' $s$ promotional in sport management in iran i, 
21-38.

15. Elsi lahti. (2013). Women and leadership factors that infulance women career success. published article En, O. F. W. O. M. (2016). Barriers and Bias, 66.

16. Gaelle Ferrant, (2019.)Measuring Women's Economic Empowerment: Time Use Data and Gender Inequality

17. Gills, Stockard J,Johnson $\mathrm{m}$ \& Williams (1987) Measuring Gender Difference: The expressive dimension and critique of androgyny scales sex koles, v-9 N 17 P. 375400

18. Gell, J. H. and F. (n.d.). Women' s Leadership and Participation Praise for the book ...

19. Gray, D. E. (2004). Doing Research in the Real WorldNo Title (first). New Delhi: SAGE Publications Ltd.

20. Grint K. Problems, problems, problems: The social construction of 'leadership.' Human Relations. 2004;58(11):1467-1494. doi: $10.1177 / 0018726705061314$

21. Hall, S., \& Morillo, M. N. (2017). A Narrative Study on the Leadership Development of Female Superintendents in New Jersey.

22. Hora, E. A. (2014). Factors that affect Women Participation in Leadership and Decision Making Position, 1(2), 97-118.

23. Hull, D., \& Ward, M. (2014). Women and sport: A summary of potential issues, (February).

24. Itika, J. (2011). Fundamentals of human resource management.

25. Jacobsen, L. S., \& Studies, S. (2014). Girls and women ' $s$ experiences of Gender-Based Barriers in Sports in Zambia.

26. Joyce B. and Showers B. (1995) Student achievement through staff development (2nd edn), White Plains, NY, Longman.

27. Kiev,( 2011).Women's Participation in Politics and Decision-Making in Ukraine: Strategy Paper

28. Lapchick,R.(2007)racial and gender report card .orlando,fl; the institute for diversity and ethics in sport at the divas sport business management graduate program .university of central Florida

29. M'mbaha, J. M. (2012). Experiences of Women In Sports Leadership In Kenya.published article

30. Massengale, D. (2009). The Underrepresentation of women in interscholastic sport leadership: A qualitative study on the effects of role incongruity by.

31. Massengale, D., Lough, N., Massengale, D., \& Lough, N. (2017). Women Leaders in Sport Viewpoint Women Leaders in Sport: Where' s the Gender Equity?, 3084(April). https://doi.org/10.1080/07303084.2010.10598 455

32. Mugari, A., \& Masocha, V. (2015). An Analysis of Gender Equity in Sport Leadership: The Women' s Spoken Mind, 2(7), 63-67.

33. Mugenda, m.o and mugenda (2003), (2008). Research methods quantitative and Qualitative approaches, Nairobi: act press

34. Mwisukha, A., \& Rintaugu, E. G. (2013). Insights into the Under-Representation of Women in Sports-Leadership in Kenya, 3(5), 102-108.

https://doi.org/10.5923/j.ijas.20130305.02

35. Repository, I. (2012). The role of women in decision-making positions : the case of Israeli sport organisations, 270.

36. Taylor, P., Pfister, G., \& Radtke, S. (2009). European Journal of Sport Science Sport , women, and leadership: Results of a project on executives in German sports organizations, (January 2015), 37-41. https://doi.org/10.1080/17461390902818286

37. To, P., The, P., Of, G., Beijing, T. H. E., Platform, T. H. E., \& Action, F. O. R. (2007). Women, gender equality and sport Women, gender equality and sport, (December).

38. Wamaitha, K. J. (2015). gender representioan.Watt, D. C. (2003). Sports Management and Administration 2nd Edition.Women in Leadership : Understanding the gender gap. (2013), (June).

39. Yimenu, B. G. (2016). Women Political Participations at a Local Government in 
Ethiopia : The Case of Sebeta Town, 49

40. Olum, D. Y. (2004). Modern Management Theories And Practices. African, East Banking, Central. Kenya.

41. Vienna,(2010). Development through Football Sustaining the potential of the first African World Cup Conference Report

42. Watt, D. C. (2004). Sports Management and
Administration 2nd Edition.Taylor \& Francis e-Library,ISBN 0-203-38060-6 Master e-book ISBN, British Library. 